\title{
Detection of IgM against Dengue Virus in Clinically Suspected Patients Presenting at a TertiaryCare Centre, Narayani Zone, Nepal
}

Hari P Nepal ${ }^{1}$, Shamshul Ansari ${ }^{1}$, Narayan Gyawali ${ }^{2,3}$, Rajendra Gautam ${ }^{1}$, Rama Paudel ${ }^{4}$, Sony Shrestha ${ }^{1}$, Brihaspati Rimal ${ }^{5}$, Anju Acharya ${ }^{1}$, Moti L Chapagain $^{1}$ and Andrew W Taylor-Robinson ${ }^{3^{\star}}$

${ }^{1}$ Department of Microbiology, Chitwan Medical College Teaching Hospital, Bharatpur, Nepal

${ }^{2}$ Department of Microbiology, Nepal Medical College, Kathmandu, Nepal

${ }^{3}$ School of Medical \& Applied Sciences, Central Queensland University, Rockhampton, Australia

${ }^{4}$ Department of Pharmacology, College of Medical Sciences-Teaching Hospital, Chitwan, Nepal

${ }^{5}$ Department of Biochemistry, Chitwan Medical College Teaching Hospital, Bharatpur, Nepal

"Corresponding author: Andrew W Taylor-Robinson, School of Medical \& Applied Sciences, Central Queensland University, Bruce Highway, Rockhampton, QLD 4702, Australia, Tel: 61749232008; E-mail: a.taylor-robinson@cqu.edu.au

Rec date: Apr 08, 2014; Acc date: May 23, 2014; Pub date: May 26, 2014

Copyright:@ 2014 Nepal HP, et al. This is an open-access article distributed under the terms of the Creative Commons Attribution License, which permits unrestricted use, distribution, and reproduction in any medium, provided the original author and source are credited.

\section{Abstract}

Background: The global prevalence of dengue has increased dramatically in recent decades, with currently 50 million clinical cases and up to 5 million hospitalisations annually. Caused by one of five closely related but antigenically distinct virus serotypes (DEN-1 to DEN-5), dengue is an emerging mosquito-borne viral disease and an important public health problem in Nepal.

Objectives: This study was designed to determine the occurrence of dengue in clinically suspected patients in Narayani Zone, Central Nepal.

Methods: A descriptive cross-sectional study was conducted between January 2010 and December 2011 at Chitwan Medical College Teaching Hospital, Bharatpur, the fifth largest city of Nepal. A total of 590 blood samples were collected and processed for anti-dengue immunoglobulin (Ig)M by antibody isotype-capture enzyme-linked immunosorbent assay.

Results: Positive detection of anti-dengue IgM was found in $8.5 \%$ of patients (50/590 cases). The highest number of dengue cases was observed in the 21-30 years age group with greater predilection in males than in females. The positive cases showed higher frequency in winter season than at other times of year. There was a significantly greater prevalence of dengue among residents of urban locations compared to those from rural areas.

Conclusions: A high percentage of dengue positivity among suspected patients demands early investigation and careful management to prevent significant outbreaks of dengue fever and dengue haemorrhagic fever.

Keywords: Dengue; Seroprevalence; IgM; ELISA; Nepal

\section{Introduction}

Dengue Virus (DV) is a positive-strand RNA virus of the Flaviviridae family. Dengue is an acute febrile illness caused by transmission of this virus from human to human via species of Aedesaegypti and, less frequently, A. albopictus mosquitoes [1]. Five DV serotypes, DEN-1, DEN-2, DEN-3, DEN-4 and DEN-5, are responsible for the disease, the last of which was discovered only very recently [2]. The viral infection in humans causes a spectrum of illness ranging from asymptomatic or mild febrile illness, i.e. Dengue Fever (DF) to severe disease forms, i.e. Dengue Haemorrhagic Fever (DHF) and Dengue Shock Syndrome (DSS) [3]. The disease is characterised by high grade fever with headache, retro-orbital pain, skin rash, muscle or joint pain and haemorrhages [4]. Secondary Dengue Virus Infection (DVI) is associated mainly with the severe form of the disease [3].
Over the last 50 years, the global incidence of dengue has risen 30fold with increasing geographic expansion to new countries and, in the present decade, from urban to rural settings, mainly in tropical and subtropical areas. An estimated 50 million dengue infections occur annually and approximately 2.5 billion people live in dengue-endemic countries. Some 1.8 billion (more than $70 \%$ ) of the population at risk for dengue worldwide live in member states of the World Health Organization South East Asia and Western Pacific regions, which bear nearly $75 \%$ of the current global disease burden due to dengue [5].

As with other vector-borne diseases, outbreaks of DF are related to the frequent movement of people. Transmigration between Nepal and India is common due to operation of an open border policy. DF was first reported in a Japanese visitor to Chitwan District of Central Nepal in 2004 [6]. This region, located in Narayani Zone, is the site of the present study (Figure 1).Larger outbreaks were reported in nine of 75 Nepalese districts in 2006 [7]. An outbreak occurred in Nepal following the Indian, Pakistan and Bhutan epidemic of DF/DHF in September-October 2006 [8]. By 2010, there were 917 confirmed cases from 12 districts, the distribution indicating spread throughout the 
country from west to east [9]. These reports suggest that DV has been circulating in Nepal for the past several years and that the prevalence is increasing annually.

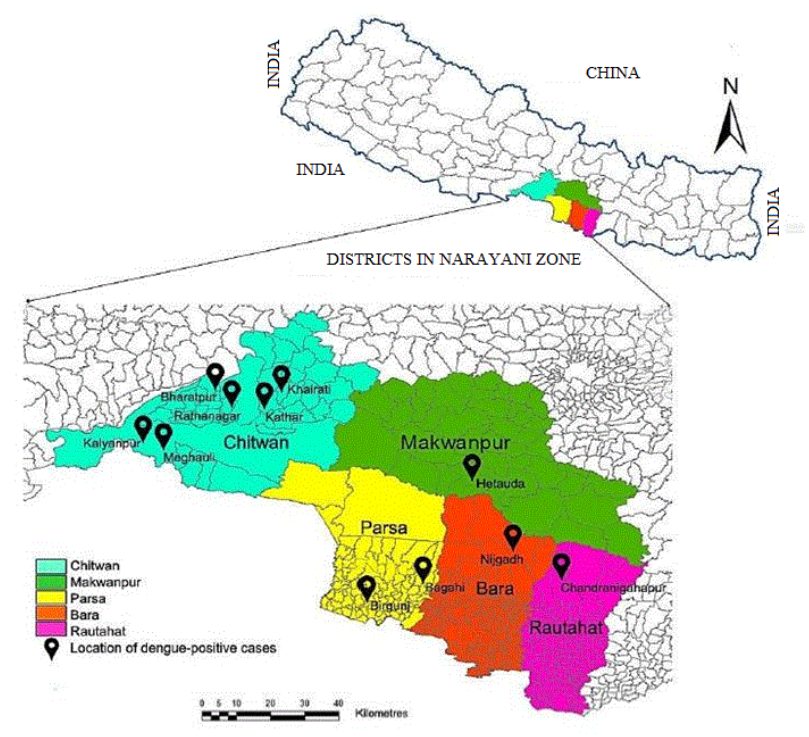

Figure 1: Map of Nepal showing the location of Narayani Zone, its constituent districts and the eleven residential locations of the 50 dengue-positive cases recorded in this study

Since dengue is a mosquito-borne disease, it is mostly found shortly after the rainy season. Aedesaegypti was first recorded in Nepal in the 1960s [10], more than 40 years before dengue was identified in the country. More recently, during entomological surveillance that followed the national dengue outbreak of 2006, this primary vector of dengue transmission was identified in five major urban areas bordering India, including the main centre for the study described herein, Bharatpur in Chitwan, and Birgunj in the neighbouring district of Parsa (Figure 1).

Although detailed entomological data are not collected on a continuous basis, it is reasonable to determine that $A$. aegypti is wellestablished in Narayani Zone but that it is particularly prevalent following the annual monsoon rains from mid-June till late September when the vast majority of precipitation falls. Where the annual rainfall is greater than $2,000 \mathrm{~mm}, A$. aegypti populations are more stable and are established in urban, semi-urban and rural areas [11]. Sitting at a low altitude of between 100-815 m, the Chitwan Valley has a tropical monsoon climate with high humidity throughout the year.

Early laboratory diagnosis of DVI is important and is performed routinely by serological test. Anti-dengue IgM antibodies appear as early as 3 days after infection and remain in circulation for 1-2 months and can be detected by IgM-capture enzyme-linked immunosorbent assay (ELISA). This procedure is used as a standard method for detecting IgM [12]. Anti-dengue IgG antibodies appear after 1 week, peak after 2-3 weeks and remain life-long in circulation.

DVI is now recognised as an emerging threat to public health in Nepal. Despite a high risk of dengue, to date there has been only limited examination for the seroprevalence of the disease. The current study was undertaken to determine the occurrence of DVI in clinically suspected patients using 'a well-established' serological method. The data presented provide valuable information regarding current prevalence of the disease in Nepal.

\section{Materials and Methods}

\section{Study design}

A descriptive cross-sectional study was conducted from January 2010 to December 2011 at Chitwan Medical College Teaching Hospital, the principal tertiary care centre in the city of Bharatpur, Chitwan District, Narayani Zone, Nepal. While samples were collected from one hospital, individuals travelled for medical attention to Bharatpur from locations all over Narayani Zone. For the denguepositive cases for which data were collected, patients came from eleven locations, six of which were within Chitwan and a further five were in neighbouring districts (Figure 1). A total of 590 samples were collected and processed for anti-dengue IgM by IgM-capture ELISA.

\section{Sample collection and storage}

Patients suspected of DVI were examined by hospital clinicians at either outpatient services or, for inpatients, when attending the emergency unit or upon admission to a ward. All cases of fever for which the individual showed two or more of the following dengue-like signs and symptoms were suspected as a DVI patient unless strong evidence of other infections were justified: retro-orbital pain; muscle and joint pain; loss of appetite; vomiting; diarrhoea; abdominal pain; metallic taste in mouth; leukopenia and thrombocytopenia in complete blood cell count; haemorrhagic manifestations.

A single blood sample (approximately 2-3 ml) was collected from each patient suspected of DVI between 3-7 days after onset of febrile illness; the mean time of sample collection was 5.5 days after the onset of symptoms. Specimen collection and separation of serumwere performed using strict aseptic precautions and following standard microbiological methods. Aliquots of sera for ELISA were prepared and stored at $2-8^{\circ} \mathrm{C}$ until tested.

\section{Detection of Anti-dengue IgM by capture ELISA}

For detection of anti-dengue IgM, a commercially available IgM capture ELISA (SD Bioline, Standard Diagnostic Inc., South Korea) was used and test results were interpreted either positive or negative according to manufacturer's instructions. The sensitivity and specificity of detection quoted by the manufacturer were $96.4 \%$ and $98.9 \%$, respectively, as evaluated by the US Centers for Disease Control and Prevention by comparison to a 'gold standard' haemagglutination inhibition test [13]. The negative control provided by the manufacturer was anti-dengue IgG/IgM antibody-negative human serum maintained in proclin 300 preservative. This diagnostic kit provided qualitative detection of IgM antibodies specific to DV in human serum, dependent on the following principle. A 96-well microtitre plate was pre-coated with mouse monoclonal anti-human IgM antibodies in each well. During a first incubation, any antidengue IgM antibody present in patient serum was bound to mouse monoclonal anti-human IgM antibodies. This was then bound to a complex of dengue antigen and mouse monoclonal anti-dengue horse radish peroxidase conjugate. Following further incubation, all unbound material was removed by aspiration and washing. The residual enzyme activity found in the wells was directly proportional to the dengue IgM antibody concentration in patient serum, as evidenced 
Citation: Nepal HP, Ansari S, Gyawali N, Gautam R, Paudel R, et al. (2014) Detection of IgM against Dengue Virus in Clinically Suspected

Page 3 of 7

by incubating the solid phase with the substrate solution tetramethylbenzidine. Colorimetric reading was performed using a spectrophotometer at $450 \mathrm{~nm}$.

\section{Interpretation of test results}

The test results were recorded and interpreted as either positive or negative on the basis of absorbance with respect to a cut-off value determined as the mean absorbance of the negative controls +0.300 . If absorbance of a sample was greater than cut-off, it was considered positive for anti-dengue IgM; in contrast, if absorbance was less than cut-off, the sample was registered as negative.

\section{Statistical analysis}

Data were analysed using Statistical Package for Social Science version 20 (SPSS v.20). Unless otherwise stated, univariate analysis was performed by chi-square test, with a difference of $\mathrm{P}<0.05$ considered to be statistically significant. In order to analyse association between districts to dengue-positive results Fisher's test was used, also using $95 \%$ confidence intervals.

\section{Ethical approval}

Ethical clearance for conducting the study was attained from the Institutional Review Committee of Chitwan Medical College Teaching Hospital. Consent from individual patients was obtained prior tobloodcollection.

\section{Results}

Of a total of 590 samples collected and processed, anti-dengue IgM antibodies were found in $50(8.5 \%)$ samples. All of the dengue-positive cases were local to residents of Narayani Zone (Figure 1); none was imported.

\section{Age- and Gender-Wise Distributionof Cases}

From 590 suspected cases of dengue, the highest number, 166 (28.1\%), belonged to the 21-30 years age group whereas the lowest number, 9 (1.5\%), belonged to the age group below 10 years. Genderwise, $48.3 \%$ of suspected cases were males $(285 / 590)$ and $51.7 \%$ were females $(305 / 590)$ (Table 1).

Among a total of 50 positive cases, the highest number, 22 (44.0\%), belonged to the 21-30 years age group. In contrast, there was not a single positive case in the age group below 10 years. Gender-wise, $62 \%$ of positive cases were males (31/50) and 38\% were females (19/50). This gender bias, a male to female ratio of $1.6: 1$, was statistically significant $(\mathrm{P}<0.05)($ Table 1$)$.

\begin{tabular}{|l|l|l|l|l|l|l|}
\hline $\begin{array}{l}\text { Age } \\
\text { group }\end{array}$ & \multicolumn{3}{|l|}{ Total suspected cases $(n=590)$} & \multicolumn{4}{|c|}{ Positive cases (n=50) } \\
\hline Years & Male & Female & Total (\%) & Male & Female & Total (\%) \\
\hline$\leq 10$ & 5 & 4 & $9(1.5)$ & 0 & 0 & 0 \\
\hline $11-20$ & 60 & 51 & $\begin{array}{l}111 \\
(18.8)\end{array}$ & 4 & 3 & $7(14.0)$ \\
\hline
\end{tabular}

\begin{tabular}{|l|l|l|l|l|l|l|}
\hline $21-30$ & 67 & 99 & $\begin{array}{l}166 \\
(28.1)\end{array}$ & 13 & 9 & $22(44.0)$ \\
\hline $31-40$ & 61 & 62 & $\begin{array}{l}123 \\
(20.8)\end{array}$ & 8 & 3 & $11(22.0)$ \\
\hline $41-50$ & 37 & 34 & $71(12.0)$ & 2 & 1 & $3(6.0)$ \\
\hline$>50$ & 55 & 55 & $\begin{array}{l}110 \\
(18.6)\end{array}$ & 4 & 3 & $7(14.0)$ \\
\hline Total & 285 & 305 & 590 & 31 & 19 & 50 \\
\hline
\end{tabular}

Table 1: Age and gender-wise distribution of dengue cases in 2010 and 2011 detected from clinically suspected patients presenting at Chitwan Medical College Teaching Hospital, Bharatpur, Nepal

\section{Monthlydistribution of positive cases}

In 2010, 21 of 60 suspected cases tested positive foranti-dengue IgM detection (35\%) (Table 2). Most of the cases (19 of 21) were detected in December. The other two cases were found in November, while there were not any cases reported in previous months. In 2011, 29 of 530 suspected cases tested positive for IgM (5.5\%). Most cases (8 of 29) occurred in January, followed by February (6cases) (Figure 2).

\begin{tabular}{|c|c|c|c|c|}
\hline Year & 2010 & & 2011 & \\
\hline Month & Total & PositiveN (\%) & Total & $\begin{array}{l}\text { PositiveN } \\
(\%)\end{array}$ \\
\hline January & 0 & 0 & 34 & $8(23.5)$ \\
\hline February & 2 & 0 & 22 & $6(27.3)$ \\
\hline March & 2 & 0 & 32 & 0 \\
\hline April & 2 & 0 & 28 & $2(7.1)$ \\
\hline May & 2 & 0 & 29 & 0 \\
\hline June & 0 & 0 & 21 & $2(9.5)$ \\
\hline July & 1 & 0 & 25 & 0 \\
\hline August & 2 & 0 & 80 & $3(3.8)$ \\
\hline September & 4 & 0 & 88 & $3(3.4)$ \\
\hline October & 9 & 0 & 104 & $4(3.8)$ \\
\hline November & 5 & $2(40.0)$ & 48 & $1(2.0)$ \\
\hline December & 31 & $19(61.3)$ & 19 & 0 \\
\hline Total & 60 & $21(35.0)$ & 530 & $29(5.5)$ \\
\hline
\end{tabular}

Table 2: Monthly percentage detection of confirmed positive dengue cases in 2010 and 2011 inclinically suspected patients presenting at Chitwan Medical College Teaching Hospital, Bharatpur, Nepal 
Citation: Nepal HP, Ansari S, Gyawali N, Gautam R, Paudel R, et al. (2014) Detection of IgM against Dengue Virus in Clinically Suspected

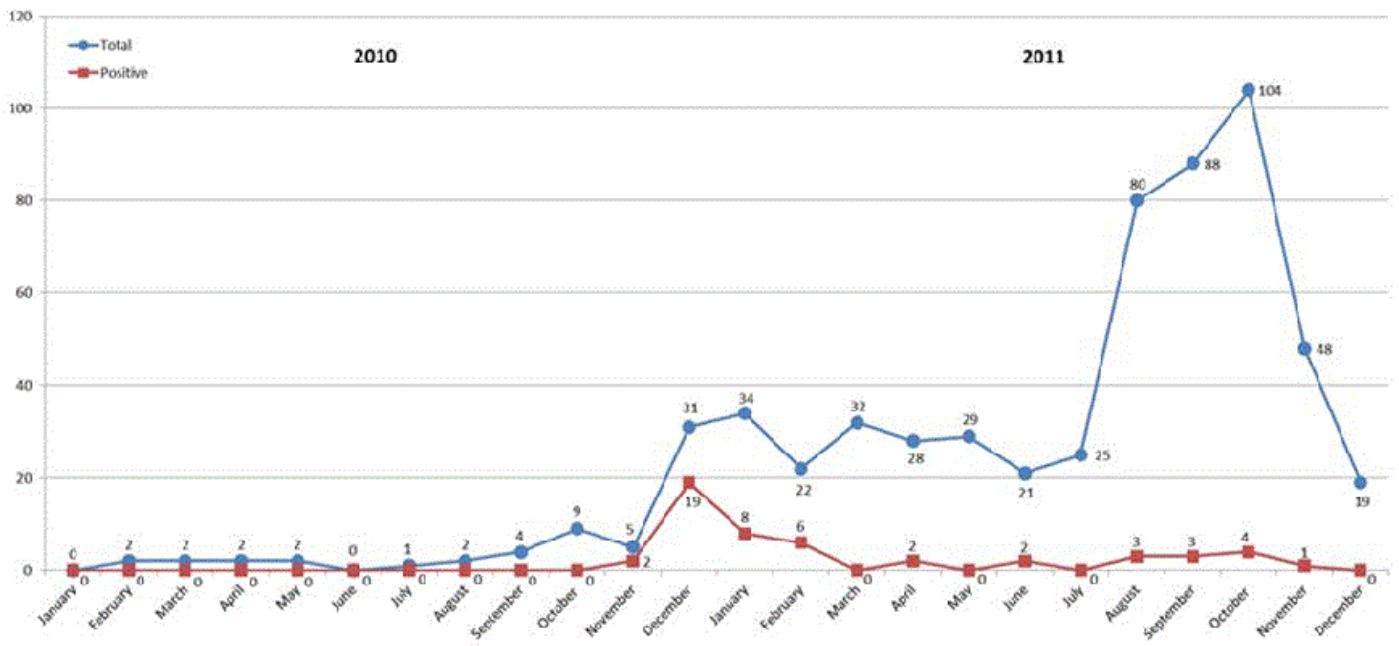

Figure 2: Monthly distribution of clinically suspected (blue) and confirmed positive (red) cases of dengue in 2010 and 2011 detected from patients presenting at Chitwan Medical College Teaching Hospital, Bharatpur, Nepal

\section{Seasonal variation of positive cases}

For both years studied, most of the cases were seen during the winter season: 19 cases in 2010 and 13 cases in 2011. There were no positive reportsfor the summer and spring seasons of 2010 (Figure 3).

\section{Regional variation of positive cases}

There was no significant difference observed for the prevalence of dengue among suspected cases between each of the five different districts of Narayani Zone from which samples were collected during the study period January 2010 to December $2011(\mathrm{P}=0.59)$ (Table 3). The majority of samples $(461 / 590 ; 78.1 \%)$ were collected from Chitwan, with a very similar distribution between urban and rural residency of patients $(217,47.1 \%$ to $244,52.9 \%)$. Overall, 39 of 277 suspected cases from an urban location were determined to be denguepositive (14.1\%). In contrast, only 11 of 313 suspected cases from a rural setting tested positive (3.5\%). This difference between detection of dengue in urban and rural areas was statistically significant $(\mathrm{P}<0.001)$.

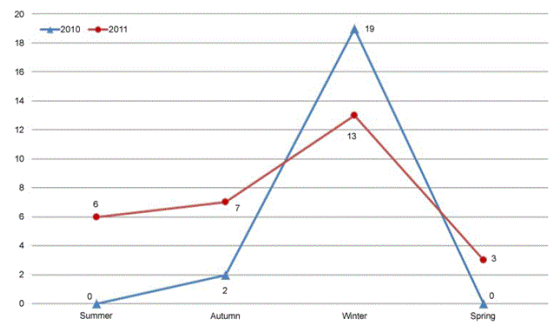

Figure 3: Seasonal distribution of dengue cases in 2010 and 2011 detected from clinically suspected patients presenting at Chitwan Medical College Teaching Hospital, Bharatpur, Nepal

\begin{tabular}{|c|c|c|c|c|c|}
\hline District & Residency & $\begin{array}{l}\text { Suspected } \\
\text { cases }\end{array}$ & $\begin{array}{l}\text { Dengue- } \\
\text { positive } \\
\text { cases } \\
(\%)\end{array}$ & $\begin{array}{l}\text { Positive/Total } \\
\text { (\%) }\end{array}$ & $\begin{array}{l}P \\
\text { value }\end{array}$ \\
\hline \multirow[t]{2}{*}{ Bara } & Urban & 10 & $2(20.0)$ & \multirow[t]{2}{*}{$3 / 36(8.3)$} & \multirow[t]{11}{*}{0.59} \\
\hline & Rural & 26 & $1(3.8)$ & & \\
\hline \multirow[t]{2}{*}{ Chitwan } & Urban & 217 & 27 (12.4) & \multirow[t]{2}{*}{$36 / 425(8.5)$} & \\
\hline & Rural & 244 & $9(3.7)$ & & \\
\hline \multirow[t]{2}{*}{ Makwanpur } & Urban & 12 & $3(25.3)$ & \multirow[t]{2}{*}{$3 / 23(13.0)$} & \\
\hline & Rural & 11 & 0 & & \\
\hline \multirow[t]{2}{*}{ Parsa } & Urban & 9 & $4(44.4)$ & \multirow[t]{2}{*}{$5 / 28(17.9)$} & \\
\hline & Rural & 24 & $1(4.2)$ & & \\
\hline \multirow[t]{2}{*}{ Rautahat } & Urban & 29 & $3(10.3)$ & \multirow[t]{2}{*}{$3 / 37(8.1)$} & \\
\hline & Rural & 8 & 0 & & \\
\hline \multirow[t]{3}{*}{ Total } & Urban & 277 & 39 (14.1) & \multirow[t]{2}{*}{$50 / 590(8.5)$} & \\
\hline & Rural & 313 & $11(3.5)$ & & $<0.001$ \\
\hline & & 590 & $50(8.5)$ & & \\
\hline
\end{tabular}

Table 3: Regional distribution of dengue cases in 2010 and 2011 in different districts of Narayani Zone, detected from clinically suspected patients presenting at Chitwan Medical College Teaching Hospital, Bharatpur, Nepal

\section{Discussion}

Dengue is an important emerging disease of the tropical and subtropical regions of the world. In common with other vector-borne diseases, dengue requires conducive predisposing conditions for endemicity and outbreaks. The countries of South East Asia share such 
common features as large human populations, rapid urbanisation, development activities and monsoon rains. Urban populations now constitute the natural reservoir and travelers are the predominant factor for dissemination of viruses between countries [14].

In Nepal, the first case of dengue was detected in a traveler from India ten years ago, since when DV has circulated in the Nepalese population. Over the intervening decade dengue has occurred regularly with periodic surges in the number of cases [15]. In this study, $8.5 \%$ of patients were serologically positive for DVI. The positivity rate concurs with observations of $10.4 \%$ and $9.0 \%$ from Nepal in 2001 and 2012, respectively [16,17], and 13.7\% from Bangladesh in 2002 [18]. While a rate of $19.7 \%$ has been reported from India in 2011 [19], this higher prevalence rate may be due to its endemic nature in that country. The age-wise distribution of seropositive cases shows that a statistically significant proportion of cases was in the 21-30 years age group as compared to other age groups $(\mathrm{P}<0.05)$. This supports observations from Nepal, India and Bangladesh [20-22].

A higher prevalence rate of anti-dengue IgM antibody in males has been reported from Nepal $[17,20]$ and from India [19,23]. Herein, the prevalence of dengue-positive cases was also biased towards males over females by a factor of $1.6: 1 \quad(\mathrm{P}<0.05)$. This difference is probably due to a gender-related variance in lifestyle, namely the relatively higher exposure of males over females to an outdoor environment through farming and other occupations.

Several mathematical models have been developed to account for the seasonality of disease outbreaks and of vector distribution and abundance. These incorporate such factors as rainfall, air temperature, humidity, type of land, mosquito density and mosquito bite rate $[24,25]$. In the present study, cases of dengue were reported all year round, albeit at a very low level in spring and summer months, so it was possible for DV to be transmitted irrespective of prevailing climatic conditions. However, the preponderance of anti-dengue IgM antibody-positive cases was reported in autumn and especially winter for both 2010 and 2011. This was indicative of a cyclic increase in the occurrence of DF consequent to the monsoon season in June to September each year, which would trigger an explosion in the population of the $A$. aegyptimosquito vector for dengue transmission. This finding is in agreement with a report from Bangladesh [18]. At this time of year, outside activity and mobility of people is high, thereby increasing exposure to mosquitoes, especially of adult males. Farmers are harvesting rice crops in the relatively low-lying, hot and humid Chitwan Valley and other regions of the Terai, a belt of marshy grassland, savannah and subtropical broadleaf forests located south of the outer foothills of the Himalaya and north of the great plains of the Ganges and Brahmaputra rivers. In addition, the occurrence in autumn and winter of major Nepalese religious and cultural festivals, including Dashain, Tihar, Losar and New Year, contributes to an upsurge in external pursuits. This marks the holiday season, the most popular period for Nepalese economic and educational migrants to neighbouring India to return to their family home.

The consensus view from previous studies conducted in a variety of global settingsis that dengue is essentially a disease of urban environments [26-29]. The present study corroborates this finding for the Terai southern lowlands of Nepal. Urban and suburban areas provide numerous artificial breeding sites for mosquitoes in a built environment containing a relatively high density of human habitation. This is especially true in developing countries where urbanization is often less managed [30]. In contrast, studies from Thailand,
Cambodia. IndiaandSri Lanka have reportedahigher prevalence of dengue in rural locations [31-34]. In each instance, it was noted that conditions which facilitate vector breeding were more common than is typical for a rural area. Thus,in the context of human geography what is important to DV epidemiology is not theextent of urbanization per sebut the existence ofa habitat that favours a stable population of $A$. aegypti. Conditions conducive to mosquito propagation are met more often in the city than in the countryside.

While cross-reactivity of IgM antibodies from patients with DV and Japanese Encephalitis (JE) is a recognised phenomenon [35], the very low prevalence of the latter, and of other flaviviruses, in Narayani Zone makes this highly unlikely to be a confounding factor in this study. Indeed, Nepal has experienced a remarkable reduction in disease burden after mass immunizations against JE from 2005 to 2010, in marked contrast to the expansion of DVI over the same period [36]. Such is the infrequency of confirmed cases of JE it is no longer a notifiable disease [9]. However, the theoretical, if not practical, limitation of the IgM capture ELISA is acknowledged, so it would be desirable to seek confirmation by other means of the results attained by this assay. In this regard, it should be noted that facilities for molecular diagnosis were not available for this study and are not routinely accessible in Nepal and other developing countries. In preliminary evaluations, two standard methods of diagnosis were tested, ELISA and a rapid immunochromatographictest. The latter did not prove sufficiently reliable with regard tobothsensitivity and specificity, soELISA was chosen for subsequent analysis of samples in this study.

As this study was conducted at the principal tertiary care centre in the main city of Chitwan -to which people travelled considerable distances from both urban and rural locations for treatment- we consider that our findings are illustrative of suspected dengue cases in Narayani Zone in 2010-11. Of the 50 cases determined to be positive for DVI, 7 were patients who were admitted to a hospital emergency unit with haemorrhagic signs and symptoms (of a total of 13 cases admitted with suspected dengue). These individuals presented with acute symptoms and would have had fever for an extended period prior to hospitalisation. As the remaining 43 cases were from outpatients departments, where patient records are either not taken or stored routinely, records for these patients are not complete. Thus, while we regard the findings for inpatients as representative of all those with haemorrhagic symptoms who were examined upon presentation at the tertiary care centre, this cannot be confirmed. Furthermore, in Nepalese culture attendance at a general practitioner's clinic is not routine practice.

For the majority of clinically suspected cases of DVI which were determined to be seronegative, hospitalization could have been due to one of several other febrile illnesses that occur in Chitwan. Whatever the cause, there was a peak of suspected cases of DVI observed between August-November 2011, most of which were diagnosed as dengue-negative. According to the national daily newspaper, The Kathmandu Post, the number of patients suffering from viral fever increased markedly in Chitwan during the autumn season of 2011. In this period, over $35 \%$ of patients attending hospitals were found to have a febrile illness [37]. In particular, viral respiratory tract infections of unknown aetiology are common. Other possible causes include leptospirosis, brucellosis, malaria, kala-azar, bacteraemia, enteric fever and PUO (pyrexia of unknown origin) [9]. Although testing for anti-dengue IgM was performed routinely, a definitive diagnosis for all the samples collected was not possible. 
Page 6 of 7

In the absence of specific treatment for DF, disease management is mainly supportive. There are no vaccines currently commercially available [38]. Therefore, early diagnosis and vector control is the only method by which dengue may be controlled [39]. A rapid immunochromatograpic test to detect NS1 antigen and IgM antibodies should be available at primary and rural health centres so that cases can be diagnosed early and thus managed properly. There is a pressing need for a long-term vector control strategy in order to prevent dengue outbreaks; simultaneously, this would solve the public health problem caused by other mosquito-borne infectious diseases such as chikungunya, JE, malaria and filariasis.

Prevention or reduction of DV transmission depends primarily on control of the mosquito vectors or interruption of human-vector contact. A determined effort is required to instigate long-term preventive measures for vector control through controlled urbanisation and appropriate piped water supply to shanty towns. This should be combined with elimination of pools of stagnant water that serve as foci for mosquito breeding, a control strategy that is acknowledged locally but which requires increased public awareness and community participation [40]. Programs for raising community awareness, together with social mobilization, are key elements of the control strategy [39]. National partnerships involving government bodies, research institutions and the private sector, as well as international collaborations, will strengthen greatly national programs for dengue surveillance, preparedness and response. The most vital component of such activity, however, is the leadership and political will to support preparedness planning and to drive implementation of orchestrated response schemes to counter outbreaks and epidemics.

\section{Conclusions}

Dengue is becoming an emerging problem in Narayani Zone, Central Nepal. The high rate of detection reported here, $8.5 \%$ of clinically suspected patients, demands early investigation and careful management. IgM capture ELISA, as was used in this study, in our informed opinion remains a reliable and routine method for the diagnosis of dengue in Nepal and similarly less-developed countries. National control programs should address this major public health issue in all its aspects including diagnosis, clinical management and continued surveillance. Moreover, capacity building should aim to provide the infrastructure to facilitate molecular laboratory confirmation of virus detection and to enable virus isolation.

\section{Conflict of Interests}

The authors declare no conflict of interests

\section{Authors' Contributions}

HPNepal, SAnsari, N Gyawali, RGautam and AAcharya conceived the design of the study and took part in data collection, processing and analysis. HPNepal, SAnsari,N Gyawali and AW Taylor-Robinson prepared the manuscript with help from $\mathrm{R}$ Paudel, SShrestha and B Rimal. R Gautam, AAcharya and M Chapagain supervised execution of the work and paper writing. AW Taylor-Robinson provided advice on interpretation of data and statistical analysis. All authors critically reviewed the manuscriptduring preparation and approved the final version.

\section{Acknowledgements}

The authors thank the laboratory staff of the Department of Virology/Immunology, Chitwan Medical College Teaching Hospital for provision of reagents and technical advice. They are grateful for the cooperation of those patients who participated in this study.

\section{References}

1. Gubler DJ (1998) Dengue and dengue hemorrhagic fever. ClinMicrobiol Rev 11: 480-496.

2. Normile D (2013) Tropical medicine. Surprising new dengue virus throws a spanner in disease control efforts. Science 342: 415.

3. Rothman AL (2004) Dengue: defining protective versus pathologic immunity. J Clin Invest 113: 946-951.

4. World Health Organization (1997) Dengue hemorrhagic fever: diagnosis, treatment and control. Geneva, Switzerland.

5. World Health Organization (2009) Dengue guidelines for diagnosis, treatment, prevention and control. Geneva, Switzerland.

6. Pandey BD, Rai SK, Morita K, Kurane I (2004) First case of Dengue virus infection in Nepal. Nepal Med Coll J 6: 157-159.

7. Epidemiology and Disease Control Division (2008) Annual report 2006-2007. Department of Health Services, Ministry of Health, Government of Nepal.

8. Singh B (2007) Dengue outbreak in 2006. Failure of public health system? Indian J Community Med 32: 99-100.

9. Epidemiology and Disease Control Division (2012) Annual report 2010/2011. Department of Health Services, Ministry of Health, Government of Nepal.

10. Gautam I, Dhimal M, Shrestha SR, Tamrakar AS (2009) First record of Aedesaegypti (L.) vector of dengue virus from Kathmandu, Nepal. J Nat HistMus 24: 156-164.

11. World Health Organization/Nepal Health Research Council (2009) Environmental conditions associated with vector of dengue and corrective actions for its prevention in Nepal. Kathmandu, Nepal.

12. Kuno G, Cropp CB, Wong-Lee J, Gubler DJ (1998) Evaluation of an IgMimmunoblot kit for dengue diagnosis. Am J Trop Med Hyg 59: 757-762.

13. Hunsperger EA, Yoksan S, Buchy P, Nguyen VC, Sekaran SD, et al. (2009) Evaluation of commercially available anti-dengue virus immunoglobulin M tests. Emerg Infect Dis 15: 436-440.

14. Mahmood BAI, Mahmood SAI (2011) Emergence of dengue in Bangladesh a major international public health concern in recent years. J Environ Manage 2: 35-41.

15. Pun SB (2011) Dengue: an emerging disease in Nepal. JNMA J Nepal Med Assoc 51: 203-208.

16. Sherchand JB, Pandey BD, Haruki K, Jimba M (2001) Serodiagnosis of Japanese encephalitis and dengue virus infection from clinically suspected patients of Nepal. J Inst Med Nepal 23: 26-31.

17. Shah Y, Khadka G, Gupta GP, Adhikari N, Poudel A, et al. (2012) Serodiagnosis of dengue virus in different hospitals of Nepal. Int J Infect Microbiol 1: 58-62.

18. Dahal EB, Banu D, Talukder KR, Chowdhury MJH, Bangali AM, et al. (2002) Sero-epidemiological study of dengue/dengue haemorrhagic fever in a metropolitan hospital in Bangladesh. Dengue Bull 26: 1-6.

19. Garg A, Garg J, Rao YK, Upadhyay GC, Sakhuja S (2011) Prevalence of dengue among clinically suspected febrile episodes at a teaching hospital in North India. J Infect Dis Immunol 3: 85-89.

20. Sah OP, Subedi S, Morita K, Inone S, Kurane I, et al. (2009) Serological study of dengue virus infection in Terai region, Nepal. Nepal Med Coll J 11: $104-106$.

21. Gupta E, Dar L, Kapoor G, Broor S (2006) The changing epidemiology of dengue in Delhi, India. Virol J 3: 92. 
Citation: Nepal HP, Ansari S, Gyawali N, Gautam R, Paudel R, et al. (2014) Detection of IgM against Dengue Virus in Clinically Suspected Patients Presenting at a TertiaryCare Centre, Narayani Zone, Nepal. J Trop Dis 2: 139. doi:10.4172/2329-891X.1000139

Page 7 of 7

22. Rahman M, Rahman K, Siddque AK, Shoma S, Kamal AH, et al. (2002) First outbreak of dengue hemorrhagic fever, Bangladesh. Emerg Infect Dis 8: 738-740.

23. Neeraja M, Lakshmi V, Teja VD, Umabala P, Subbalakshmi MV (2006) Serodiagnosis of dengue virus infection in patients presenting to a tertiary care hospital. Indian J Med Microbiol 24: 280-282.

24. Nakhapakorn K, Tripathi NK (2005) An information value based analysis of physical and climatic factors affecting dengue fever and dengue haemorrhagic fever incidence. Int J Health Geogr 4: 13.

25. Bartley LM, Donnelly CA, Garnett GP (2002) The seasonal pattern of dengue in endemic areas: mathematical models of mechanisms. Trans $\mathrm{R}$ Soc Trop Med Hyg 96: 387-397.

26. Mendonça HF, Ferreira AL, Santos CB, Rezende HR, Ferreira GE, et al. (2011) Breeding sites of Aedesaegypti in metropolitan vacant lots in Greater Vitória, State of Espírito Santo, Brazil. Rev Soc Bras Med Trop 44: 243-246.

27. Mulligan K, Elliott SJ, Schuster-Wallace C (2012) The place of health and the health of place: dengue fever and urban governance in Putrajaya, Malaysia. Health Place 18: 613-620.

28. Padmanabha H, Durham D, Correa F, Diuk-Wasser M, Galvani A (2012) The interactive roles of Aedesaegypti super-production and human density in dengue transmission. PLoSNegl Trop Dis 6: e1799.

29. Murray NE, Quam MB, Wilder-Smith A (2013) Epidemiology of dengue: past, present and future prospects. ClinEpidemiol 5: 299-309.

30. Gubler DJ (2011) Dengue, Urbanization and Globalization: The Unholy Trinity of the 21(st) Century. Trop Med Health 39: 3-11.

31. Chareonsook O, Foy HM, Teeraratkul A, Silarug N (1999) Changing epidemiology of dengue hemorrhagic fever in Thailand. Epidemiol Infect 122: 161-166.
32. Kumar A, Sharma SK, Padbidri VS, Thakare JP, Jain DC, et al. (2001) An outbreak of dengue fever in rural areas of northern India. J Commun Dis 33: 274-281.

33. Vong S, Khieu V, Glass O, Ly S, Duong V, et al. (2010) Dengue incidence in urban and rural Cambodia: results from population-based active fever surveillance, 2006-2008. PLoSNegl Trop Dis 4: e903.

34. Reller ME, Bodinayake C, Nagahawatte A, Devasiri V, KodikaraArachichi W, et al. (2012) Unsuspected dengue and acute febrile illness in rural and semi-urban southern Sri Lanka. Emerg Infect Dis 18: 256-263.

35. Singh KP, Mishra G, Jain P, Pandey N, Nagar R, et al. (2014) Copositivity of anti-dengue virus and anti-Japanese encephalitis virus IgM in endemic area: co-infection or cross reactivity? Asian Pac J Trop Med 7: 124-129.

36. Dumre SP, Shakya G, Na-Bangchang K, Eursitthichai V, Rudi Grams H, et al. (2013) Dengue virus and Japanese encephalitis virus epidemiological shifts in Nepal: a case of opposing trends. Am J Trop Med Hyg 88: 677-680.

37. The Kathmandu Post (2011) Viral fever up in Chitwan.

38. Sanyal S, Taylor-Robinson AW (2013) Host-virus interactions in dengue infection indicate targets for detection and therapeutic interventions. Immun Dis 1: 1-4.

39. Griffiths K, Banjara MR, O'Dempsey T, Munslow B, Kroeger A (2013) Public health responses to a dengue outbreak in a fragile state: a case study of Nepal. J Trop Med: 158462.

40. Dumre SP (2011) Dengue outbreaks in Nepal: are we prepared? The Kathmandu. 